\section{Bioética e as diretrizes curriculares nacionais do curso de medicina}

\section{Bioethics and national medical school curriculum guidelines}

Ana Maria de Oliveira 1

1 Programa de Doutoramento em Bioética. Faculdade de Medicina. Universidade do Porto. Alameda Prof. Hernâni Monteiro, 4200319. Porto, Portugal. E-mail: anamadoida@bol.com.br

\begin{abstract}
The article discusses various bioethical issues addressed by the National Curriculum Guidelines (DCN) for medical schools, a document approved in 2001 by the Ministries of Health and Education which sets out guidelines for medical training Bioethics permeates all the DCN guidelines for medical schools. This means that the discipline performs an integrating role in the medical training process. In view of observations backing the hypothesis that education is determined by society, this new paradigm helps to instill the new Brazilian health system, the Unified Health System, with its nuanced and mixed models of health care. Bioethics is given legitimacy by the DCN. It remains for the teaching profession to ensure that it is consolidated in academic circles, as an indispensible discipline, if biological knowledge is to be pursued in a prudent fashion promoting humane values and an ethics of life.
\end{abstract}

Key words Education, medical, Bioethics, Curriculum

\section{Resumo}

O artigo apresenta uma análise dos aspectos bioéticos contidos nas Diretrizes Curriculares Nacionais (DCN) do curso de medicina, documento aprovado em 2001 pelos Ministérios da Educação e da Saúde e que propõe diretrizes para a formação do profissional médico. O campo da Bioética permeia todas as diretivas das DCN do curso de Medicina. Isso credita à disciplina um status de eixo integrador no processo de formação de médicos. Considerando as observações que reforçam a tese de que a sociedade é que conforma a educação, esse novo paradigma contribui para efetivação do sistema de saúde brasileiro, o Sistema Único de Saúde, com todos os nuances e hibridizações de modelos de atenção. A Bioética está legitimada nas DCN. Resta ao aparelho formador garantir que ela se consolide na academia, enquanto ciencia propositiva imprescindivel para se alcançar a necessária prudência ao conhecimento biológico, associando aos valores humanos a ética da vida.

Palavras-chave Educação médica, Bioética, Currículo 


\section{Introdução}

No contexto das mudanças curriculares nos cursos superiores na área da Saúde no Brasil vários acontecimentos nos níveis federativo e intersetorial, a partir da década de 1980, conspiraram para se almejar a tão esperada ordenação dos recursos humanos no Sistema Único de Saúde (SUS). Os primeiros eventos ocorreram no clímax do movimento da Reforma Sanitária no ano de 1986:1 a Primeira Conferência Nacional de Recursos Humanos e a histórica 8a Conferência Nacional de Saúde, marcos condicionantes da criação do SUS e da organização e regulação do trabalho na saúde, consagrado no artigo 200, inciso III da Constituição de $1988 .^{2}$

Orientada pelas diretrizes políticas defendidas e apregoadas pelo Movimento da Reforma Sanitária foi criada a Lei Orgânica da Saúde (LOS) de 1990 que define uma política para os trabalhadores da saúde. ${ }^{3}$ Essa política teve o objetivo de organizar um sistema de formação em todos os níveis de ensino e colocar os serviços de saúde como campos de ensino-aprendizagem, expressão da indissociabilidade entre a assistência, a gestão e a formação. $\mathrm{Na}$ mesma ordem de interesse, à época, também convergia um movimento educacional nacional promovido pelas entidades médicas, docentes, instituições de ensino e estudantes que equacionava a necessidade de medidas de controle da abertura de novas escolas de medicina, a melhoria do ensino e a avaliação das escolas médicas. ${ }^{4}$

Em 1996 foi promulgada a Lei de Diretrizes e Bases da Educação Nacional n ${ }^{\circ} 9.3945$ que confere às Instituições de Ensino Superior o desenho de currículos inovadores, possibilita a flexibilização desejada, favorecendo a implantação das Diretrizes Curriculares Nacionais (DCN) de modo a concretizar a relevância social da ação acadêmica e a reforçar a formação profissional como política de interesse mútuo entre os Ministérios da Educação e da Saúde. 6

Partindo desse momento histórico, pretende-se desenvolver o tema, historicizando a educação médica, contextualizando a política de saúde e de educação e situando a dimensão ética contida nas DCN, enfatizando a importância da disciplina Bioética como eixo estruturante e favorecedor da implementação e efetivação do SUS

\section{Revisitando a educação médica}

Marcado historicamente pelo modelo francêsnapoleônico que o inspirou, o ensino superior brasileiro praticamente, se definiu como um sistema de ensino formador de profissionais para o mercado de trabalho. A influência que a escola francesa de filosofia e medicina exercia sobre a elite médica brasileira no início do século pode ser encontrada nas memórias do primeiro Congresso Brasileiro de Práticos ocorrido em 1922.7 Nesse encontro memorável, pela primeira vez os interesses dos profissionais estão em destaque em detrimento do técnicocientifico e três perfis de prática médica são reconhecidos: o generalista, o especialista e o higienista. Essas três tendências presentes à época resistem ao tempo.

A medicina atual é marcada por extraordinários avanços tecnológicos e científicos, técnicas e procedimentos diagnósticos, farmacológicos e terapêuticos cada vez mais sofisticados e caros. O aprisionamento do saber médico aos paradigmas da medicina orgânica tem levado as escolas médicas a concentrar seus conteúdos programáticos numa racionalidade orgânico-tecnicista, que visa, sobretudo, capacitar o futuro profissional na arte da semiótica, preparando-o para diagnosticar e curar enfermidades orgânicas. Assim, a educação médica é um terreno de conflitos e de lutas de interesses e de poder, como acontece em toda situação em que convivem sujeitos sociais com distintas concepções, compromissos e interesses.

A grande guinada na educação médica mundial ocorreu após um amplo trabalho desenvolvido por uma comissão especialmente constituída pela Fundação Carnegie cuja coordenação coube ao educador americano, Abraham Flexner. Segundo Ros, 8 o relatório Flexner publicado em 1910, passou para a história do ensino médico como um marco no estabelecimento de uma nova maneira de produzir médicos. Desde essa época já se observa a subordinação histórica da instituição de ensino ao setor saúde e aos interesses sociais hegemônicos. E a prática médica está ligada à transformação histórica do processo de produção econômica.

Entender os caminhos percorridos pela educação médica será importante para situar o ensino da ética e da bioética no cenário brasileiro. Segundo Almeida ${ }^{9}$ houve antecedentes históricos internacionais que contribuíram para as inovações apontadas pelas novas diretrizes curriculares, tais como: a) a decisão da Assembléia Mundial de Saúde de 1977 que estabeleceu a meta de 'saúde para todos no ano 2000'; b) a Conferência de Alma-Ata em 1998 que elegeu a atenção primária de saúde como estratégia prioritária para atingir a meta referida; c) vários programas e/ou experiências inovadoras no campo da formação de profissionais de saúde, espe- 
cialmente em escolas médicas do sudeste brasileiro. Uma dessas foi a proposta "Uma Nova Iniciativa na Educação dos Profissionais de Saúde: União com a Comunidade (UNI)"10 que foi concebida com a participação de líderes do movimento da educação dos profissionais de saúde de várias áreas e do movimento de reforma do setor de saúde existente na América Latina, particularmente do movimento pela Reforma Sanitária Brasileira.

Até recentemente, na história da educação médica brasileira, mais do que o desafio da mudança imperava a falta de idéia para onde e como ir. $\mathrm{Na}$ busca de caminhos, destaca-se a Comissão Interinstitucional Nacional de Avaliação do Ensino Médico (CINAEM), da qual o Conselho Federal de Medicina (CFM) participou decisivamente, que iniciou seus trabalhos de avaliação da escola médica no final dos anos 1980, findou em 2000 e cujos resultados, ainda que parciais e preliminares, apontaram as fragilidades e potencialidades do ensino médico brasileiro. 4

\section{O horizonte da bioética e as diretrizes curricu- lares}

Uma articulação entre os Ministérios da Educação e da Saúde que envolveu o Conselho de Secretários Municipais de Saúde (CONASEMS), mobilizou a Câmara de Graduação da Educação Superior do Conselho Nacional de Educação do Brasil para a aprovação das Diretrizes Curriculares Nacionais do Curso de Graduação em Medicina em 2001.6 Tal normativa tem como objetivo nortear a formação geral e específica do médico com ênfase na promoção, prevenção, recuperação e reabilitação da saúde, e é considerado um dos primeiros passos dado pelos Ministérios da Saúde e da Educação no sentido de harmonizar e direcionar a política de formação de recursos humanos em consonância com os princípios e diretrizes do SUS.

As diretrizes curriculares, no entanto, constituem-se apenas em uma indicação, uma recomendação, já que, no Brasil, as universidades gozam de autonomia que é definida na Lei de Diretrizes e Bases da Educação Nacional (LDB) como prerrogativa de criação, expansão, modificação e extinção de cursos e programas de educação superior, fixação dos currículos de seus cursos e programas, planificação e programação de pesquisa científica e de atividades de extensão, além da elaboração da programação dos cursos. 5

No cumprimento das prerrogativas normativas e autorizativas e deveres do Estado, o Ministério da Educação e o Conselho Nacional de Educação impõem restrições à autonomia em temas considerados como de responsabilidade pública relevante. Por conseguinte, a relevância pública da saúde, definida constitucionalmente, se constitui razão suficiente para o setor Educação incorporar a autonomia universitária à gestão das políticas públicas de saúde, garantindo a sintonia entre as diretrizes constitucionais do SUS e as curriculares nacionais, para efetivação do SUS.

Sabe-se que a formação se constitui em um dos componentes na concretização das metas de saúde; ainda se considera um entrave, a compreensão da gestão da formação como atividade meio e secundária à formulação de políticas de atenção à saúde. Tradicionalmente, fala-se da formação como se os trabalhadores pudessem ser administrados como um dos componentes matriciais de um espectro de recursos, quais sejam materiais, financeiros, microestruturais e como se fosse possível apenas 'prescrever' habilidades, comportamentos e atitudes aos trabalhadores do setor para que as devidas ações e serviços sejam implementados com a qualidade requerida.

No âmbito das Diretrizes Curriculares Nacionais está explicitada a redefinição do perfil do profissional médico, que incorpora o trabalho como princípio educativo e que indica a inserção dos estudantes em múltiplos cenários de práticas, em complexidade crescente, por meio da integração ensino-serviço. É um momento de ação-reflexãoação como estratégia do cotidiano de ensinar e aprender.

No princípio do documento, no artigo $3^{\circ}$ há referência ao perfil do egresso. Textualmente, preconiza: 6

\footnotetext{
[...] que o médico tenha formação generalista, humanista, crítica e reflexiva, capacitado a atuar pautado nos princípios éticos, no processo saúde-doença em seus diferentes níveis de atenção (...) com senso de responsabilidade social e compromisso com cidadania, como promotor da saúde integral do ser humano.
}

A preocupação com o ensino sistemático da ética médica remonta a Assembléia Médica Mundial, em 1999, ocasião em que foi aprovada a resolução da Inclusão da ética médica e dos direitos humanos nos currículos das escolas de medicina de todo mundo, a qual recomendava o ensino da ética e dos direitos humanos, por admitir que na contemporaneidade, os recursos tecnológicos deveriam ser usados racionalmente, tendo o ser humano como fim e não um meio. $11 \mathrm{Na}$ verdade, ao analisar o documento, presume-se que se refere à ética aplicada, ou seja, à 
bioética como estudo sistemático da conduta humana na área das ciências da vida e cuidado da saúde, enquanto essa conduta é examinada à luz dos valores e princípios morais. 12

A preocupação com a ética na ciência e tecnologia foi determinante para a Organização das Nações Unidas para a Educação, Ciência e Cultura (UNESCO), em 2002, escolher ética como uma das cinco áreas prioritárias de atuação, inclusive com a introdução de programas de ensino de ética, dentre outras atividades. 13 Tendo como missão nos termos do seu ato constitutivo, promover a solidariedade moral e intelectual da humanidade, esta organização tem iniciado ações pontuais para fomentar a reflexão sobre o ensino da bioética no mundo, inclusive a criação da cátedra de Bioética UNESCO em parceria com a Universidade de Brasília e a criação da RedBioetica de educação.14,15

A Bioética, entendida como disciplina que aborda os conflitos morais e a tomada de decisão no exercício da prática médica, se apresenta como uma grande possibilidade de inovação curricular para preparar o profissional nas deliberações profissionais, promover a responsabilidade social e a cidadania, competências requeridas na formação e que ultrapassam o contido nos ensinamentos da Deontologia e Diceologia.16 À guiza de esclarecimento, competência é definida como a habilidade de mobilizar diferentes capacidades, entendida como combinação de atributos: conhecimento (saber, domínio cognitivo); habilidades (saber fazer, domínio psicomotor); e atitudes (saber ser e saber conviver, domínio afetivo). 17

A educação em bioética é uma área temática prioritária na América Latina e para o seu desenvolvimento é necessária a formação de profissionais tanto da saúde e de outras áreas nessa disciplina. É necessário formular objetivos, conteúdos, metodologias e formas de avaliar e aperfeiçoar a educação em bioética em todos os níveis. 12,18,19

Os Conselhos de Medicina tiveram e têm relevante papel na divulgação e na discussão da formação ética na graduação. E, mais do que isto, o Conselho Federal de Medicina, numa posição politicamente correta e preventiva ao erro médico, vem recomendar aos Conselhos Regionais de Medicina que promovam a instituição de programas destinados ao ensino dos princípios da ética médica durante o período escolar sempre que possível em colaboração com as faculdades de medicina e com os diretórios acadêmicos; determinar aos médicos, em função docente formal ou não a supervisão ética e técnica dos estudantes de medicina no trato com os pacientes, sem perder de vista a função social da medicina. 18

Com o surgimento da bioética iniciou-se no Brasil uma discussão sobre a inclusão dos assuntos relacionados a essa disciplina na formação dos alunos de medicina. Nos dias atuais em que a ciência e a técnica adquiriram tamanha força econômica e transformadora sobre a vida e a condição humana, o controle ético passa a ser uma iniciativa impostergável. Assim nasceu a bioética, uma das áreas de estudo que mais vem crescendo nos últimos 30 anos em todo mundo, desde seu nascedouro no início dos anos 1970 nos Estados Unidos. 15

Há autores que fazem sérias críticas a respeito do ensino atual da bioética nas escolas médicas brasileiras e são incisivos ao dizer que ele se caracteriza ainda, por uma visão marcadamente deontológica, necessária, mas insuficiente para atender às necessidades de formação do profissional, pois não tem a capacidade de responder aos dilemas morais apresentados pelos novos avanços das ciências, em especial pelas novas tecnologias aplicadas à biomedicina. 19

Desde então, apesar dos esforços, ainda há carência de publicações sobre esse tema, tanto na metodologia e estratégias de ensino quanto nos resultados, efetividade e perfil ético dos egressos, tanto na literatura internacional20 quanto nacional.18,19,21 Toda profissão tem uma cultura específica e esta cultura possui valores igualmente específicos. A transmissão de valores e a conformação da identidade profissional na graduação são aspectos muito pouco discutidos na educação médica. Estes fatos são profundamente preocupantes para a educação médica, assim como são críticos acerca da qualidade dos conteúdos e dos métodos que se está ensinando.

Vale ressaltar que é inquietante constatar que a eventual introdução de uma nova disciplina, por si só é insuficiente para produzir qualquer mudança significativa no ensino da ética; mesmo que os programas de disciplinas de ética ou bioética reconheçam e fomentem a existência de uma moral interna, o estudante longe de enriquecer sua perspectiva ética, pode ver dissipar sua perspicácia moral e seu interesse pelos aspectos éticos profissionais. A formação médica está longe de se restringir a uma atividade 'asséptica' de transmissão de conhecimentos ou de capacitação técnica.

O filósofo Morin (2003: 87-88)22 num ensaio sobre a educação do futuro chama a atenção de que, ainda não incorporamos a mensagem de Eurípedes, que é de estarmos prontos para o inesperado. Ele exorta que: 
[...] a grande incerteza a enfrentar decorre do que chamamos de ecologia da ação, que compreende três princípios: o circuito risco/precaução(...) circuito fins/meios (e) circuito ação/contexto

Dessa maneira a educação para ensinar a condição humana deverá ocorrer em contextos geradores de atitudes, comportamentos e habilidades para com o inesperado, a incerteza. Partindo do pressuposto de que a bioética é o cenário multidisciplinar indispensável para a humanização da humanidade rumo à futuridade, a educação para as incertezas necessita de uma base epistemológica que possa emancipar o homem; que seja centrada na realidade, oportunizando a tão necessária reflexão sobre o serestar-fazer no mundo.

No momento, a bioética chama a atenção para posicionamentos contrastantes e para as incertezas num contexto de pluralismo moral, diante de um manancial de idéias, percepções e posições filosóficas. O diálogo e o respeito pelo diferente e pelo diverso são atitudes necessárias e fundamentais ao encontro com o outro. Esse deve ser o norte para o processo ensino-aprendizagem da bioética, como movimento teórico e ação deliberada durante o curso de medicina, que possibilitará a formação de médicos em consonância com o preconizado nas DCN.

O artigo $4^{\circ}$ das Diretrizes Curriculares Nacionais 6 estabelece que a formação do médico tem por objetivo atingir os conhecimentos, habilidades e competências necessárias para as seguintes áreas: a) atenção à saúde; b) tomada de decisões; c) comunicação; d) liderança; e) administração e gerenciamento; f) educação permanente. 6 Dentre os vários objetivos e competências citados destaca-se que os profissionais devem realizar seus serviços dentro dos mais altos padrões de qualidade e dos princípios da ética/ bioética.

Todas essas qualificações exigidas na formação do médico estão situadas no campo da competência moral e dizem respeito à teoria ética e filosofia moral, ou seja, à reflexão filosófica sobre a natureza e a função da moralidade e as convenções sociais sobre o comportamento humano.23 Discorrendo sobre a nomenclatura, o termo ética vem do grego ethos e moral do latim mores, mas para alguns autores são considerados equivalentes. Para os que fazem a diferenciação, e que adotamos no texto, pode-se dizer que a moral tem um caráter histórico e social. 19

Vale dizer que o homem ao mesmo tempo em que é herdeiro, é criador de cultura, e só terá vida moral, se diante da moral constituída, for capaz de propor a moral constituinte, aquela que é construída a partir das experiências vividas. Portanto, é preciso considerar os dois pólos contraditórios do pessoal e do social numa relação dialética. A moral será imposta ao indivíduo e deriva de esquemas e normas sociais, enquanto a ética é do indivíduo e emergirá da análise subjetiva que cada um fizer do mundo.

Cohen e Segre 24 propõem a diferenciação entre a moral e a ética a partir de alguns aspectos relevantes: a moral pressupõe três características: a) seus valores não são questionados; b) eles são impostos; c) a desobediência as regras pressupõe um castigo. Por outro lado, a ética refere-se a: a) percepção do conflito em questão (consciência); b) autonomia (condição para posicionar-se frente a relação emoção $\mathrm{x}$ razão, sendo que a escolha é consciente e autônoma); c) coerência frente ao seu enfoque e a escolha.

A competência moral que se apregoa nas DCN se refere à competência ética, a consciência da existência de conflito e a deliberação autônoma e coerente frente ao mesmo. Assim, a educação moral curricular e formal (ética deontológica e bioética) objetiva favorecer o desenvolvimento da capacidade do individuo de lidar com a diversidade de opiniões e situações e ao mesmo tempo, em que delibera por meio de reflexão moral autônoma.

$\mathrm{O}$ artigo $6^{\circ}$ da normativa curricular prevê que os conteúdos essenciais do curso de medicina devem estar relacionados com o processo saúde-doença do cidadão; e o artigo $12^{\circ}$ preconiza que a estrutura do curso deve ter como eixo de desenvolvimento as necessidades de saúde dos indivíduos e das populações. 6 Portanto, ao se constatar que o marco conceitual de modelo para o ensino médico é explicitamente definido pelo modelo de atenção à saúde contido nas políticas públicas, não se pode ignorar que os modelos sanitários, e em particular a prática e a educação médica, em vigor em dada sociedade estão baseados na concepção predominante do que seja o processo saúde-doença.

A partir de então, a expansão do SUS provocou um movimento paradoxal no paradigma da atenção, pois tanto houve experiências que reforçaram o modelo médico tradicional biomédico quanto geraram novas experiências de organização da atenção. ${ }^{25}$ Pois, foi nesse contexto que as DCN foram colocadas. A depender do resultado das disputas dialógicas e ideológicas que se estabelecem no interior das escolas e que por sua vez são influenciadas pelas forças externas, temos o modelo hegemônico, porém não único.

No modelo Flexneriano as dimensões política e ideológica e a do saber entendem a saúde como 
mercadoria e a doença numa concepção reducionista de um desarranjo biológico do individuo. No modelo de saúde coletiva, a saúde é almejada dentro de uma pauta de lutas pela transformação social e conquistas de direitos e cidadania. Certamente, cada um desses modelos determina qual modelo de bioética será adotado no processo de ensino-aprendizagem da disciplina no curso de medicina. Porém, a se atentar para os princípios e diretrizes do SUS, o paradigma da saúde coletiva é o que melhor atende aos avanços que estão constitucionalmente assegurados para o país. ${ }^{25}$

$\mathrm{Na}$ medida em que se compreende o processo saúde-doença de uma maneira cidadã, isto enseja posturas diferentes e modos de intervenção diversos na organização dos serviços de saúde.

A bioética se apresenta como a ciência da possibilidade de eixo epistemológico, norteador e estruturante da formação de recursos humanos em geral para atenção a saúde. A propósito do tema, há autores nacionais que creditam uma identidade "sanitária" à bioética brasileira, que na sua origem, quando se legitima como campo acadêmico, destaca sempre o interesse pelas questões de saúde pública. 26

Partindo do pressuposto de que a ciência moderna só pode se desenvolver em se livrando de qualquer julgamento de valor, obedecendo a uma única ética, a do conhecimento;22 de que docentes e discentes são seres humanos e como tal, as ações são intencionais e fundamentadas em suas concepções de mundo; e de que educação e o educar se referem a processos de comprometimento com a realidade, com o cotidiano que está diante de si, e que acontece a todo instante, teremos a Bioética como o instrumento e o veículo para se processar a aprendizagem da condição humana no mundo.

Sabe-se que a tão necessária e esperada participação, tomada de decisões, reflexão autônoma dos sujeitos envolvidos no processo ensino-aprendizagem, historicamente construído na indiferença histórica e no obscurantismo educacional e cultural representam desafios a exigir a ruptura com a concepção positivista que prioriza a racionalidade instrumental. A proposta estabelecida pelas DCN possibilita mudanças na pratica médica e na produção de atenção à saúde. E considerando que a instituição de novos cenários de prática, a valorização das dimensões psicossocial e antropológica do adoecer e a incorporação de tecnologias relacionais na formação médica possibilitam uma reorientação do olhar sobre a compreensão do processo saúde-doença e questionase a possibilidade de emergência de um novo estilo de pensamento médico. 27

\section{Considerações finais}

Verifica-se que o campo da Bioética permeia todas as diretivas das DCN do curso de Medicina, tal qual o tecido conjuntivo dá sustentação ao corpo humano. Isso credita à disciplina um status de eixo integrador no processo de formação de médicos. Ao mesmo tempo, considerando as observações que reforçam a tese de que a sociedade é que conforma a educação, esse novo paradigma para a educação médica contribui para efetivação do sistema de saúde brasileiro, o SUS, com todos os seus nuances e hibridizações de modelos de atenção.

A bioética está legitimada nas diretrizes curriculares nacionais. Resta ao aparelho formador garantir que a bioética se consolide na academia, enquanto ciência propositiva imprescindível para se alcançar a necessária prudência ao conhecimento biológico, associando aos valores humanos a ética da vida. É no diálogo com o outro que cada um é constituído, desconstruído e reconstruído, cotidianamente.

\section{Referências}

1. Brasil. Secretaria de Políticas de Saúde. Política de Recursos Humanos para o SUS: balanço e perspectivas. Brasília, DF: Ministério da Saúde; 2002. [acesso em 17 jan 2010]. Disponível em: http://bvsms.saude.gov.br/bvs/ publicacoes/cd03_16.pdf.

2. Brasil. Constituição da Republica Federativa. 1988. [acessado em 17 jan 2010]. Disponível em http://www.planalto.gov.br/ccivil_03/Constituicao/Constitu i\%C3\%A7ao.htm

3. Brasil. Lei 8.080, de 19 de setembro de 1990. Dispõe sobre as condições para promoção, proteção e recuperação a saúde, a organização e o funcionamento dos serviços correspondentes e da outras providencias. Diário Oficial da União. Poder Executivo. Brasília, DF; 20 set 1990.
4. Piccini RX, coord., Facchini LA, Santos RC. Preparando a transformação da educação médica brasileira. Projeto CINAEM III FASE. Relatório 1999-2000. Pelotas: UFPel; Ago/2000. 310 p

5. Brasil. Lei no 9.394, de 20 de dezembro de 1996. Estabelece as diretrizes e bases da educação nacional. Diário Oficial da União. Brasília, DF; 20 dez 1996.

6. Brasil. Diretrizes curriculares nacionais dos cursos de graduação em medicina. Brasília, DF; 2001

7. Pereira Neto A. Ser médico no Brasil: o presente no passado. Rio de Janeiro: Fiocruz; 2001. 
8. Ros MA. A ideologia dos cursos de medicina. In: Marins JJN, Rego S, Lampert JB, Araújo JGC, orgs. Educação médica em transformação - instrumentos para a construção de novas realidades. São Paulo: HUCITEC e ABEM; 2004. p. 224-44.

9. Almeida MJ. Educação médica e saúde: possibilidades de mudanças. Paraná: Ed. UEL; 1999.

10. Feuerwerker LCM, Sena R. A construção de novos modelos acadêmicos de atenção à saúde e de práticas sociais. In: Feuerwerker, LCM, Sena R, orgs. A educação dos profissionais de saúde na América Latina: teoria e prática de um movimento de mudança. Tomo I. São Paulo: HUCITEC; Buenos Aires: Lugar Editorial; Londrina: UEL; 1999. p. 4782 .

11. Asociación Médica Mundial. Manual de ética medica 2009. [acesso em 17 jan 2010]. Disponível em: http://www.wma.net/es/30publications/30ethicsmanual/pdf/ ethics_manual_es.pdf

12. Rego S, Rosito M, Yamada KN. Didática, formação de professores e ensino em Bioética. In: Anjos MF, Siqueira JE, orgs. Bioética no Brasil: tendências e perspectivas. São Paulo: Idéias \& Letras; 2007. p. 129-42.

13. Have HT. The activities of UNESCO in the área of ethics. Kennedy Inst Ethics J. 2006; 16: 333-51.

14. Lenoir N. Promover o ensino da bioética no mundo. Rev Bioética. 1996; 4: 65-70.

15. Hossne WS, Albuquerque MC, Goldim JR. In: Anjos MF, Siqueira JE, orgs. Bioética no Brasil: tendências e perspectivas. São Paulo: Idéias \& Letras; 2007. p. 145-60.

16. Silva RP, Ribeiro VMB. Inovação curricular nos cursos de graduação em Medicina: o ensino da ética como uma possibilidade. Rev Bras Educ Méd. 2009; 33: 134-43.

17. Ribeiro ECO, Lima VV. Competências profissionais e mudanças na formação. Olho Mágico. 2003; 10: 47-52.
18. Gomes JCM. O atual ensino da ética para profissionais de saúde e seus reflexos no cotidiano do povo brasileiro. Rev Bioética. 1996; 4: 53-64.

19. Siqueira JE, Sakai MH, Eisele RL. O ensino da ética no curso de medicina: a experiência de Londrina (UEL). Rev Bioética. 2002; 10: 85-95.

20. Eckles RE, Meslin EM, Gaffney M, Helf PR. Medical ethics education: where should web e going? a review. Acad Med. 2005; 80: 1143-52.

21. Dantas F, Sousa EG. Ensino da deontologia, ética médica e bioética nas escolas médicas brasileiras: uma revisão sistemática. Rev Bras Educ Méd. 2008; 32: 507-17.

22. Morin E. Os sete saberes necessários à educação do futuro. 8. ed. São Paulo: Cortez; Brasília: UNESCO; 2003.

23. Beauchamp TL, Childress JF. Princípios da ética biomédica. 4 ed. São Paulo: Ed Loyola; 2002.

24. Cohen C, Segre M. Definição de valores, moral, atividade e ética. In: Segre M, Cohen C, orgs. Bioética. São Paulo: EDUSP; 1995. p. 13-22.

25. Campos GWS. A clínica do sujeito: por uma clínica reformulada e ampliada. In: Campos GWS, org. A saúde paidéia. São Paulo: HUCITEC; 2003. p. 51-77.

26. Schramm FR, Anjos MF, Zoboli E. A questão das tendências epistemológicas ou de fundamentação. In: Anjos MF, Siqueira JE, orgs. Bioética no Brasil: tendências e perspectivas. São Paulo: Idéias \& Letras; 2007. p. 29-56.

27. Nogueira MI. As mudanças na educação médica brasileira em perspectiva: reflexões sobre a emergência de um novo estilo de pensamento. Rev Bras Educ Méd. 2009; 33: 26270

Recebido em 10 de maio de 2010

Versão final apresentada em 28 de julho de 2010

Aprovado em 15 de setembro de 2010 